\title{
Design and performance analysis of PV grid-tied system with energy storage system
}

\author{
Jerry Kumar' ${ }^{1}$, Nanik Ram Parhyar ${ }^{2}$, Manoj Kumar Panjwani ${ }^{3}$, Danish Khan ${ }^{4}$ \\ ${ }_{1,3,4}$ Renewable Energy School, North China Electric Power University, China \\ ${ }^{2,3}$ Department of Energy Systems Engineering, Sukkur IBA University, Pakistan \\ ${ }^{2}$ School of Information and Electronics, Beijing Institute of Technology, China
}

\begin{tabular}{l} 
Article Info \\
\hline Article history: \\
Received Jan 6, 2020 \\
Revised Jun 21, 2020 \\
Accepted Jul 11, 2020 \\
\hline Keywords: \\
Control strategy \\
Depth of discharge \\
Grid-tied system \\
Insolation \\
Inverter \\
Lithium-ion battery \\
Photovoltaic
\end{tabular}

Photovoltaic

\begin{abstract}
With the increasing demand for solar energy as a renewable source has brought up new challenges in the field of energy. However, one of the main advantages of photovoltaic (PV) power generation technology is that it can be directly connected to the grid power generation system and meet the demand of increasing energy consumption. Large-scale PV grid-connected power generation system put forward new challenges on the stability and control of the power grid and the grid-tied photovoltaic system with an energy storage system. To overcome these problems, the PV grid-tied system consisted of $8 \mathrm{~kW}$ PV array with energy storage system is designed, and in this system, the battery components can be coupled with the power grid by $\mathrm{AC}$ or DC mode. In addition, the feasibility and flexibility of the maximum power point tracking (MPPT) charge controller are verified through the dynamic model built in the residential solar PV system. Through the feasibility verification of the model control mode and the strategy control, the grid-connected PV system combined with reserve battery storage can effectively improve the stability of the system and reduce the cost of power generation. To analyze the performance of the grid-tied system, some realtime simulations are performed with the help of the system advisor model (SAM) that ensures the satisfactory working of the designed PV grid-tied system.
\end{abstract}

This is an open access article under the CC BY-SA license.

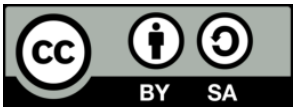

\section{Corresponding Author:}

Manoj Kumar Panjwani

Department of Energy Systems Engineering

Sukkur IBA University

Pakistan

Email: manoj.panjwani@iba-suk.edu.pk

\section{INTRODUCTION}

Renewable energies are making their mark on high in the field of solar and wind energy owing to the clean energy and its replenishing ability. Recently, clean energy resources are thoroughly being adopted and explored due to the increasing environmental concern worldwide $[1,2]$. A solar photovoltaic (PV) system is one of the important renewable energy sources that work on solar energy. The power delivered from photovoltaic panels relies upon the sun's radiation. At daytime, there is sufficient sunlight to keep the cells at most extreme yield; however, around evening time, the energy production is much lower. Despite the fact that most power is devoured during the day, it is additionally required overnight as well. Unless the photovoltaic panels are associated with the power grid, it can invert the energy utilization counter making the need to store power created during the day so it will be accessible overnight or in greatly overcast days. Energy storage systems outfit power as well as infuse that energy into the grid so suppliers can productively 
meet their requests. Grid-tied PV systems are the most popular choices when it comes to power generation and fulfills the demand of increased energy consumption. In a grid-tied photovoltaic system, surplus electricity is stored in batteries or directly fed to the electrical grid network depending on the AC or DC coupling. Grid-connected PV energy is one of the prominent renewable energy sources and has been widely investigated. Energy storage has become an important technology to overcome the shortage of electricity in peak demand. There is a need to fill the gap of financial and technical limitations in the energy storage technologies like thermal storage, pumped hydro storage, fuel cell storage, batteries, and supercapacitor [3-6]. To enhance the performance of the grid-tied PV system because of intermittent nature, battery energy storage system (BESS) is needed. This study is concerned with designing and creating dynamic control techniques with inverter interfaced BESSs, intending to make certain the proper operation of the microgrid system in islanded mode. There is a need for power management strategies in an isolated microgrid having a few small distributed generation systems. Significant frequency vibrations in independent grids require to have a single dominant energy source that can be utilized for both supplying and absorbing energy. These frequency vibrations can be mitigated by reducing the computation time using different control and power management strategies with interfaced BESS.

Site location, system type, and applications are important factors for laying out the solar PV system. Solar charge controller, battery storage systems, energy sources, and electrical loads are the important building block of the solar PV system. In this design, the calculations were done both manually and by a realtime simulation software known as the system advisor model (SAM). With the funding of the U.S. Energy Department, the National Renewable Energy Laboratory (NREL) has developed the SAM software. This software is used to design and determine the specifics of the grid-tied storage system along with analyzing the performance of the system by real-time simulations.

In this work, the grid-tied PV system consisted of $8 \mathrm{~kW}$ solar array, $600 \mathrm{~V}$ MPPT charging controller, $7.6 \mathrm{~kW}$ grid-tied inverter, $600 \mathrm{Ah}$ battery bank is designed, and the performance is determined by obtaining simulation results using SAM software. Moreover, this paper is organized as follows. Section 2 describes the literature review of the study, in section 3 research methodologies are mentioned for carrying out this work, in section 4 design of grid-tied PV system is described along with the simulation results for analyzing the performance and conclusion is given in section 5 .

\section{LITERATURE REVIEW}

Grid integrated PV systems are the most popular choices when it comes to power generation. The literature includes simulation and optimization of PV battery systems based on self-consumption. Batteries have mostly integrated with stand-alone PV systems [7]. Now, they are gaining attention in grid-connected PV systems under feed-in tariff (FiT) and time of use tariffs [8]. Even though domestic solar PV has high installation costs, it has been widely adopted by users driven by energy policies in Europe and around the globe. Large scale production of solar farms is also common due to favorable energy policies.

PV-grid tied system is comprised of PV solar array, an inverter, DC-DC converter, and the power grid. As the output power from solar panels depends upon solar irradiation thus power generation is discontinuous in this scenario. To overcome this effect, it is necessary to have a battery storage system for the smooth operation of the system. This type of grid-connected system suffers from both technical and nontechnical issues [9]. The power interruption, quality of power, islanding, issues of protection, and storage are some of the technical concerns. Issues of costs, panel cracking, labors lacking skills, and transmission line are known as non-technical issues [10].

Energy systems equipped with battery storage helps in mitigating the high-frequency intrusion, which is caused by distributed energy resources having variable nature [11]. It is a vital issue to justify the importance of battery storage in power generation networks. There is always a case when power generation does not meet with the required demand even with the distributed energy resources because of the increasing demand for electricity during peak hours. Thus indicating a poor infrastructure of power generation, transmission, and distribution [12].

Under the quantity of self-consumption battery storage system and active demand-side management were studied and concluded by Castillo-Cagigal et al. [13]. It has been found that there is a very important link between the battery storage capability and electricity energy flow. Moreover, it can be considered an important variable for decision making. The examination in [14], explored the reasonability of FiT plans for upgrading the advancement of sustainable power source advances. Lu and Shahidehpour [15] utilized a Lagrangian relaxation-based enhancement approach for determining the charging and discharging behavior of battery in a power grid to which PV energy was connected. To determine the number of batteries and PV modules for stand-alone PV systems with battery storage a formulation based on linear programming was stated by Kaushika et al. [16]. It will help in the proper operation of the PV system and achieve the hundred 
percent reliability or power supply probability (PSP) having zero loss. For the efficient working of the PV system supported by battery storage, different studies have been conducted. It was revealed by Halliday et al. [17], that PV systems with battery storage can offer lifetime capital cost for around 20 years which becomes approximately $33 \%$ of the installed system.

Voltage-current (VI) characteristic diagram of solar systems was created by Appelbaum et al. [18] to determine the load control and efficient charging and discharging of batteries. Related work on efficient battery operation was also performed by Fragaki and Markvart [19] that focused on the comparison of designing and collecting experimental data of PV systems with battery storage. In their study, they tried to develop and enhance the strategy for the effects of system memory, which was supported by the charge controller. To achieve the desired performance of recently developed EES systems have suffered in terms of achieving better response of charging and discharging efficiency, low cost, high energy density, and long life [20]. To overcome these drawbacks hybrid EES because of its better performance was proposed in his study having the potential to replace traditional energy storage. Update model named distributed energy resources customer adoption model (DER-CAM) was developed by Stadler et al. [21]. In this model, Stadler used a blended integer streamlining program which is known as an efficient program in terms of performance for distributed energy sources and battery storage systems. To reduce the overall cost and achieve peak power shaving in smart grid-connected with PV a dynamic programming model was developed by Wang et al. [22]. This dynamic program helped to achieve a profit of $73.9 \%$ by implementing the combination of lead-acid and Lithium-ion batteries.

It is said that by 2030, there will be nine times more solar PV, and five times more wind power will be implemented as compared to 2013 [23]. The cost factor in a grid-connected system with energy storage is required to be a tackle for widespread use, which increases by early diminishing of battery parts and surrounding temperature [24]. Different types of batteries depending upon the capacity, lifetime, charging, and discharging ability, safety, maintenance, and cost are widely available in the markets. Lead-acid batteries are currently utilized worldwide to help sustainable power sources. Most of the batteries available in the market have short cycles and lifetime and operate up to three or four years after proper maintenance. NickelCadmium batteries have the attributes of an excellent life cycle and the discharge rate is high. However, the materials used in Nickel-Cadmium batteries are expensive than those in Lead-Acid batteries. Lithium-ion batteries because of having high energy density, high power, and short discharge cycles are preferred for electrical vehicles and consumer appliances. However, these types of batteries suffer from overheating and burst problems [25]. Sodium-sulfur batteries that use molten salt for electrolyte, can operate at high temperatures but they discharge fully within six hours. Moreover, with series and parallel combinations of batteries more electricity can be stored and help in managing utility-scale power storage of the grid [26]. The Korean power company has planned to develop an energy storage system having the capacity of 500 MW in 8 different substations that will be utilized for frequency modulation [27]. Having the applications of frequency modulation and renewable energy sources, the energy storage system in the power grid has attracted the market share towards itself in 2015.

\section{RESEARCH METHODOLOGY}

In this section, research methodology is described for designing and developing the control strategies for the reliable operation of the microgrid system in islanded mode, which is supported with inverter interfaced BESSs. In this work, to achieve the rapid time shifting between energy consumption and generation, a dynamic control system method is developed for BESS in islanded mode. In this research, different tools are developed that can help in identifying the variation of frequency occurring because of varying load. The designed control method in this work can address both types of frequency variation caused by load and power minimization having a storage battery in a charging and discharging manner. It also maintains a state of charge (SOC) of battery in terms of safe charging and discharging status. Later, by integrating the developed control tools and designed methods in an islanded microgrid having a battery in a bi-directional resulted in minimization of variation of frequency that ultimately improved the efficiency of the designed system.

Whereas, to design the PV grid-tied system and analyze the performance of the system is also described in this section. Firstly, meteorological data sets were acquired and processed in order to obtain the most accurate data for the exact location on the planet. A calculation tool was developed in which the different data needed for the modeling and simulation like weather data, PV plant data, storage variable data, and load data, etc. is being handled. Later, a model was simulated to inject the PV plant to the grid that will allow for the fulfillment of management conditions required by the system operator. The electrical storage system (ESS) using the injection model was simulated and optimized in order to obtain the required capacity and cycles of the storage system for the different possible scenarios and ratios storage capacity/production. 
Plant production was also calculated under specific storage criteria and different parameters of injection. All the final results were summed up and concluded, and finally, the design was simulated, and its performance was analyzed by using SAM software.

The grid-tied system, coupled with battery backup, works on the functionality of time. Upon execution, the system first measures the amount of solar radiation to see if the solar modules generate enough power to charge the batteries and also supply to the AC loads through the inverter. On weak radiation days, the system uses the grid to charge the batteries and supply the difference power generated from the solar panels. For some reason, if the grid goes down, the system will check the battery status to ensure the power supply form the backup. The battery and solar panels will work in island mode like an off-grid system. If the batteries do not have enough charge, the solar panels will switch to charge the batteries first to a threshold point for discharge until the grid is back online. The following flowchart in Figure 1 gives an illustration of how the system interacts within.

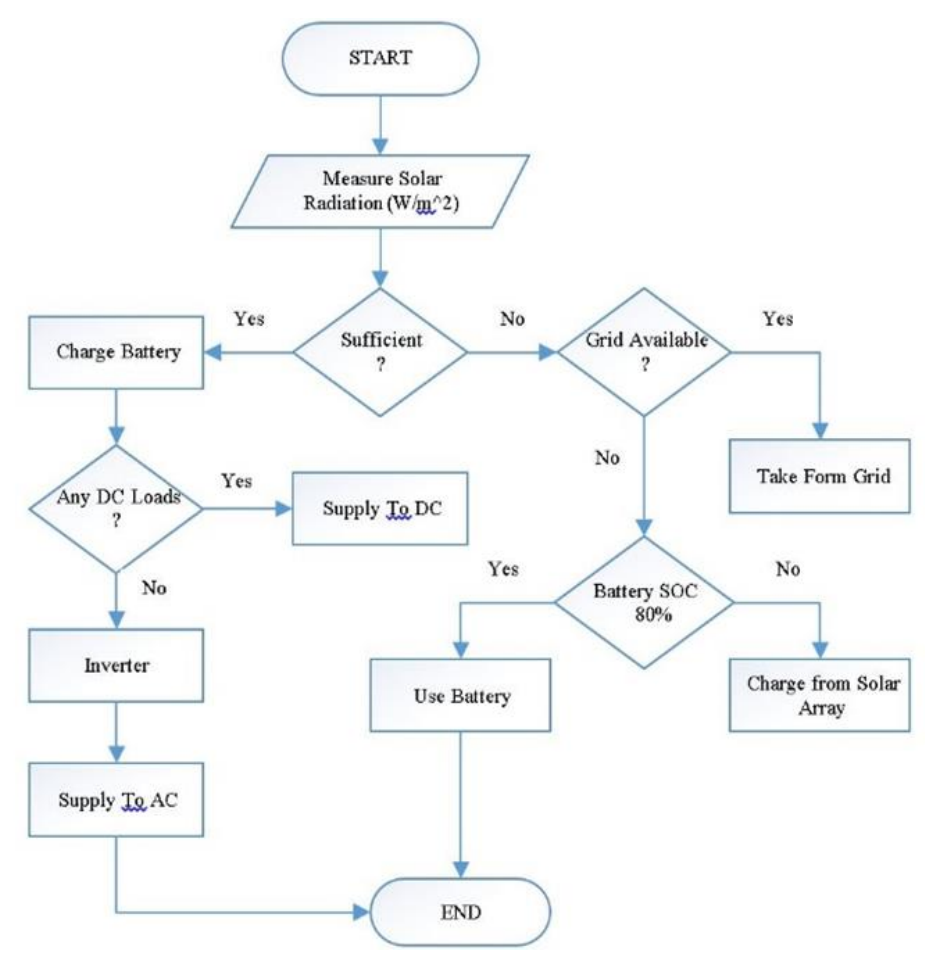

Figure 1. Grid-tied battery system algorithm flowchart

\section{RESULTS AND DISCUSSION}

This grid-tied PV system consists of $8 \mathrm{~kW}$ solar array, $600 \mathrm{~V}$ MPPT charging controller, $7.6 \mathrm{~kW}$ grid-tied inverter, and 600 Ah battery bank. The battery components can be coupled with the power grid by AC or DC mode. This system is designed by keeping in view of monthly electrical load. Moreover, the design specification of solar system components is determined by performing calculations manually and SAM software. To determine the performance of the designed grid-tied system with an energy storage system, simulation results are obtained with the help of SAM software.

\subsection{Annual load profile distribution}

The load is distributed over three primary sources of energy with solar power, battery backup, and the grid. In Figure 2, the blue and red curves represent the electricity to load from PV and Grid. In contrast, orange and green curves depict the electricity from the battery and total energy consumed by the load, respectively. During the day, the plant can provide enough power to run the household consumption without any external source unless the weather turns its production low. As seen in Figure 2, the battery runs during the evening hours to help with peak shaving and reduce the cost of electric bills. Peak shaving is used to reduce demand charges of peak loads during the evening. From 10 am to 3 pm, it can be seen that the sun is highest in the sky and it is when the solar panels will collect the most energy. If the PV system produces 
more energy than the required consumption during the day, the batteries will use the excess in the evening. In Figure 2, the orange curve shows the battery produces about $0.3 \mathrm{~kW}$ of power to lower the grid production during peak hours, especially during the evening. As a side benefit, even if the power goes out, the solar storage batteries allows us to keep power running. Normally, grid-connected solar panels also stop working during a power outage because of the safety risks of overload when the power gets restored.

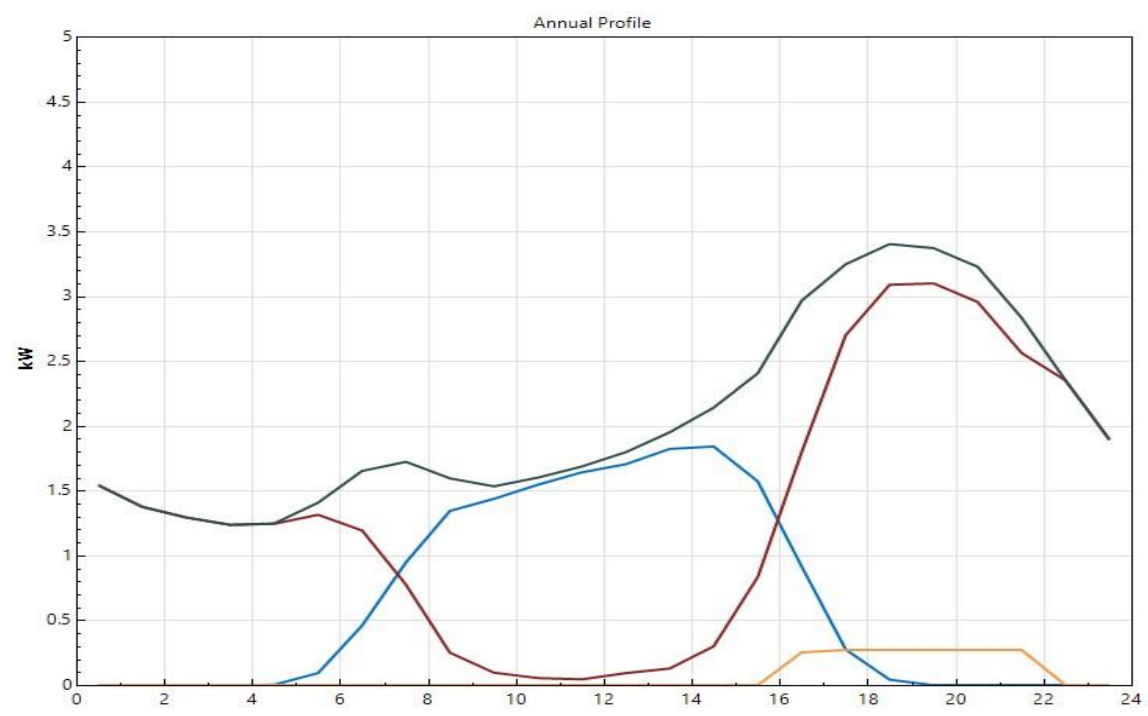

Figure 2. Electricity to load from grid, PV, and battery

\subsection{Grid-tied PV system design and simulation results}

Following Figure 3 illustrates the generation and consumption of energy from an $8 \mathrm{~kW}$ solar array for 12 months throughout the year. The generation capacity curve in orange generally takes the shape of a bell curve on clear days. The consumption load curve in blue indicates typical load peaks in the evening hours. The amount of solar energy directly corresponds to the portion of consumed power that is inside the generated PV energy. It can be determined from the results that self-consumption is better because the average use of solar energy is less than the amount of energy produced by the PV system, and it helps in lessening the burden on medium and low voltage grid.
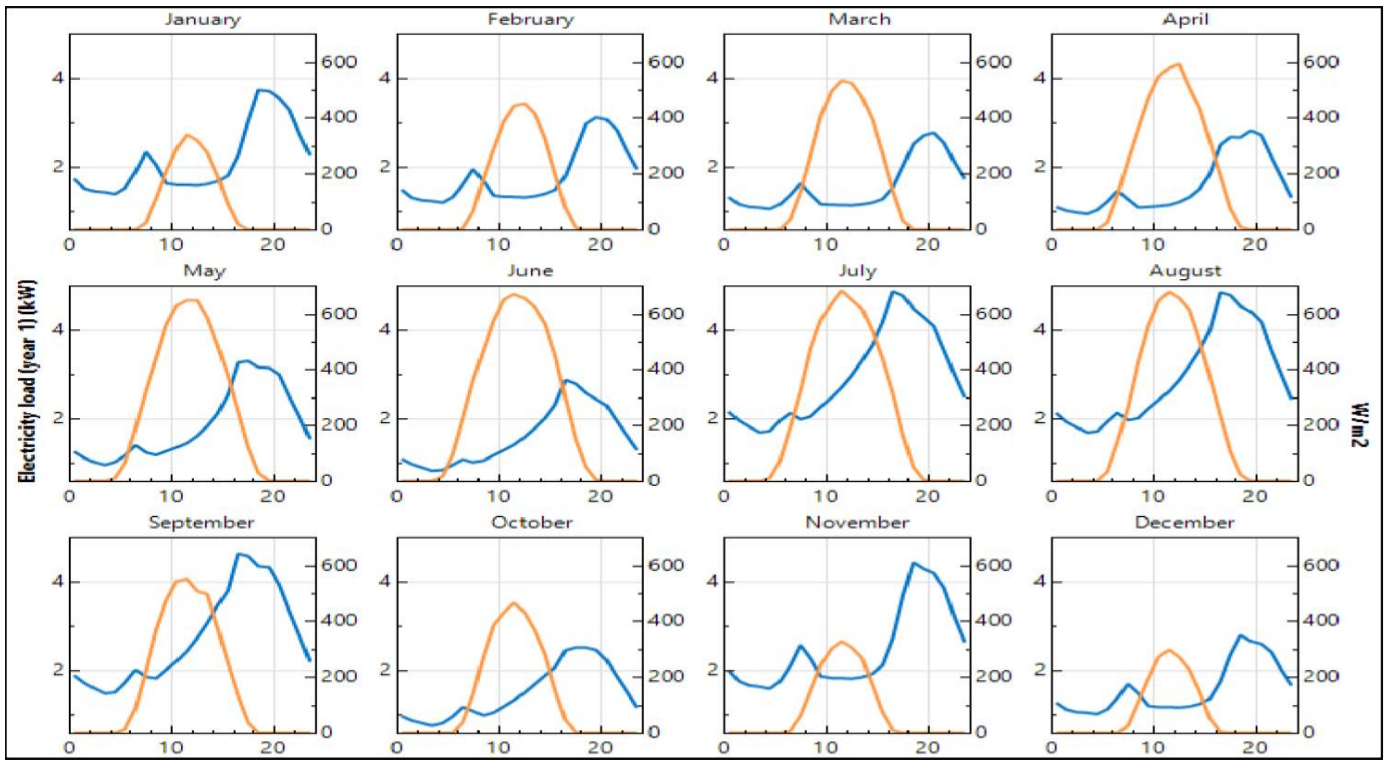

Figure 3. Graph of insolation and load vs. time (annual) 


\subsection{Battery charge and discharge dispatch times}

The cost can be minimized by charging and discharging the battery in dispatchable modes. Each hour, the system looks at the available dispatchable power sources and chooses to operate the source or the combination of sources that can produce the required amount of power and operate reverse most cheaply. There are two different strategies either to charge the battery with a grid when the battery is low or PV solar array should be used to charge the battery and grid generates power to serve the load. It's hard to know prior to the two strategies that will be optimal in any particular application. SAM software allows us to try both for optimal results shown in Figure 4.

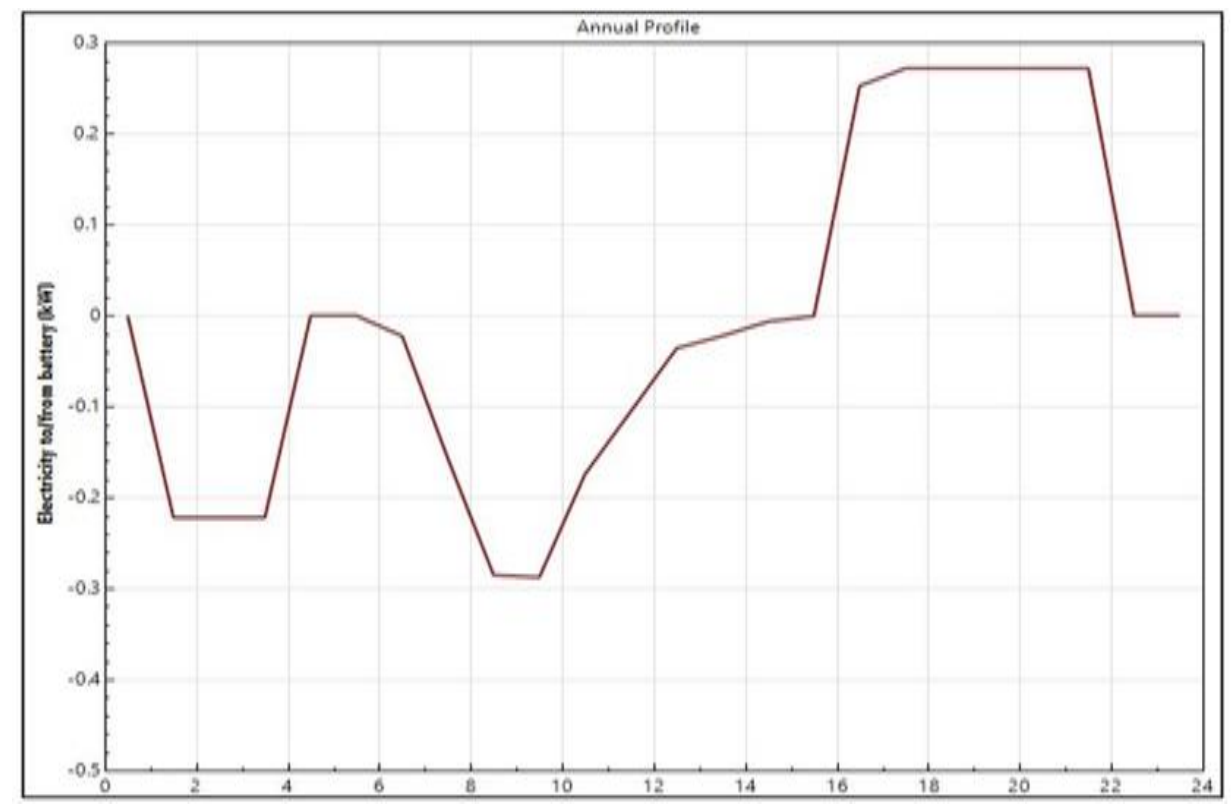

Figure 4. Electricity to battery from grid and PV array

\subsection{Unit cost simulations}

The utility company set charges according to the time of day, and the rate of utilities per unit in a day are given in Table 1 accordingly. As shown in Figure 5, the charges fluctuate from $10 \mathrm{am}$ to $8 \mathrm{pm}$. This is a strategy that the company implies for consumers to use less electricity during the day since most of the powered appliances are turned on during these hours. However, there is a constant rate from 9 pm to 9 am for consumers to enjoy their electronic comforts, such as using washing machines, dryers, etc.

Table 1. Utility rate per day

\begin{tabular}{ccr}
\hline Period & Max. Usage Unit & Buy $(\$ / \mathrm{kWh})$ \\
\hline 1 & $\mathrm{kWh}$ & 0.29101 \\
2 & $\mathrm{kWh}$ & 0.24939 \\
3 & $\mathrm{kWh}$ & 0.26789 \\
4 & $\mathrm{kWh}$ & 0.23939 \\
5 & $\mathrm{kWh}$ & 0.07289 \\
\hline
\end{tabular}

In Figure 6, the manual dispatch is carried out to optimize the battery usage of the PV system. Where numbers 1 and 2 are the charging times of the battery while 3 is the discharging time. During the day, dispatch 1 takes place to charge the batteries by the excess energy produced by the solar panels. Since the electricity rate is low during night time, dispatch 2 takes place to charge the batteries off the grid. Discharging the batteries (dispatch 3) during the evening period helps to reduce the utility bill. Though dispatch 1 is set to run the loads first before putting power into the batteries. If, in case of low power production by the solar panels, the grid will take over to cater for the difference and charge the batteries for evening peak shaving. 


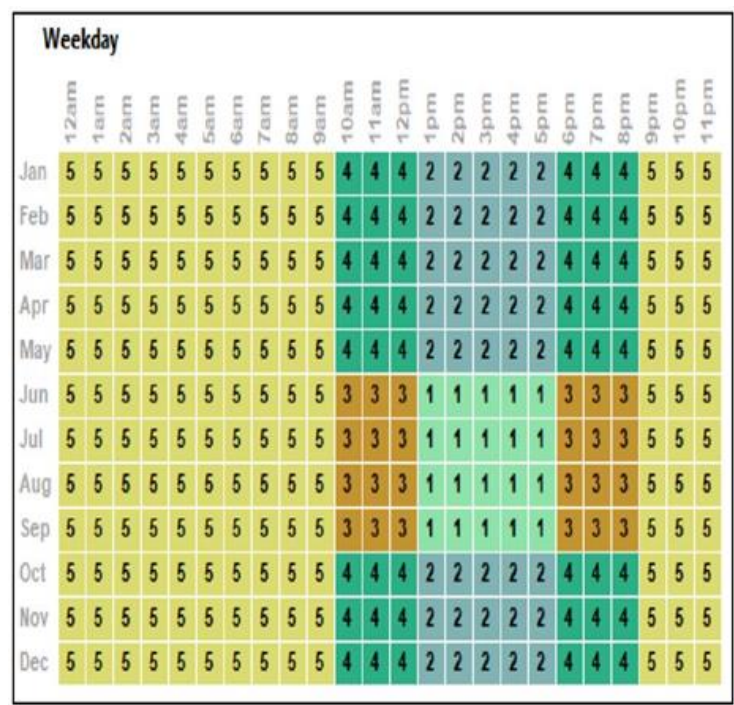

Figure 5. Annual utility rates in a day

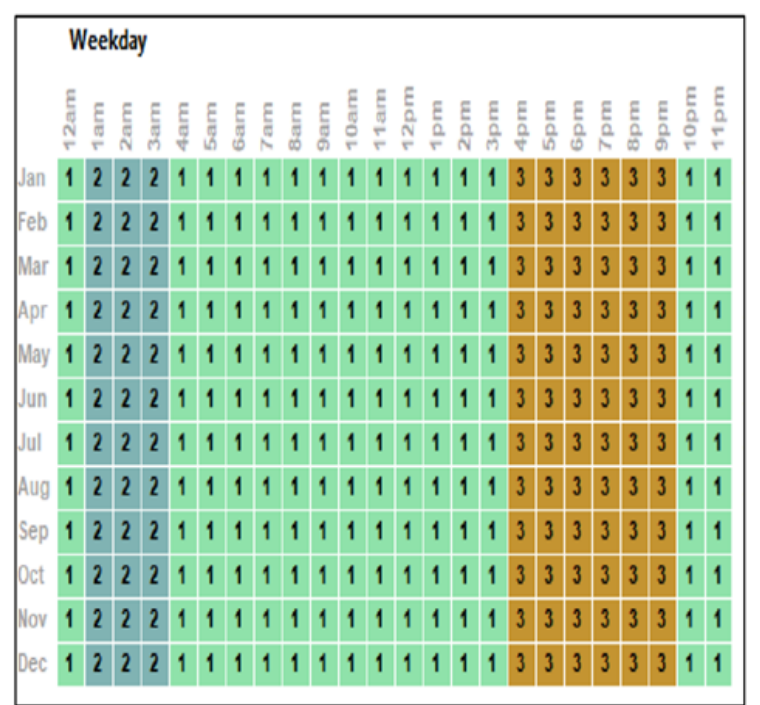

Figure 6. Manual battery dispatch

\subsection{Battery performance upon charging}

According to the simulation results in Figure 7, the lithium iron phosphate battery can hold a 92\% charge at room temperature of $10{ }^{\circ} \mathrm{C}$. The nominal bank voltage is $13.2 \mathrm{~V}$, and the charging cell voltage is $3.4 \mathrm{~V}$ at $200 \mathrm{Ah}$. Charging the battery involves three stages, which are bulk, absorption, and float. The bulk stage involves about $80 \%$ of the recharge, wherein the charger current is held constant, and the cell voltage increases $3.6 \mathrm{~V}$. The adequately sized charger manages the battery current as it will accept up to a charger capacity ( $25 \%$ of the capacity in amp hours), and will raise the battery over $40{ }^{\circ} \mathrm{C}$. The absorption stage (approximately remaining $20 \%$ ) has the charger holding the voltage at the charger's absorption voltage (between 13.2 VDC and 13.8 VDC, depending on the charger set points) and decreases the current until the battery is fully charged. The float stage is where the charge voltage is reduced between 12.2 VDC and 12.8 VDC and held constant. In contrast, the current is reduced to less than $1 \%$ of battery capacity to maintain a fully charged battery indefinitely.

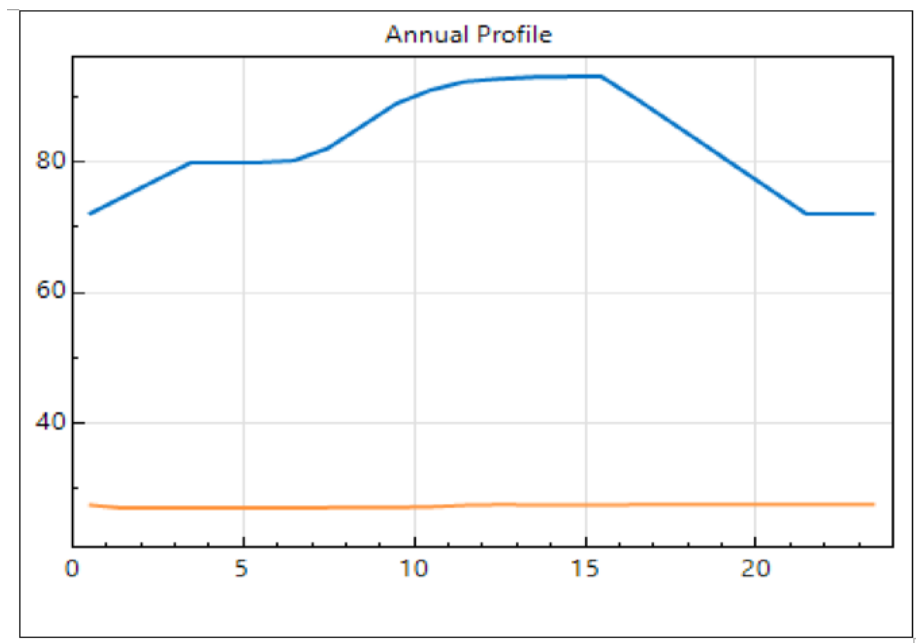

Figure 7. Battery state of charge and depth of discharge

\subsection{PV islanding and frequency control}

Islanding is the condition in which a distributed generator (DG) continues to power a location even though the electrical grid power is no longer present. It can be eliminated by using grid-tied inverter used in this design, that is always connected to the main breaker box to sell excess power to the grid, and whenever 
there is a disturbance in the grid or power outage, the Grid-Tied inverter picks up voltage disturbance from the power lines and disconnects itself from the grid and allows the workers to repair the grid without being a risk to a power source.

As shown in Figure 8 and Figure 9, the grid and inverter output are in phase and having a frequency of $60 \mathrm{~Hz}$ when it is supplying power to the household. When the grid goes down, the voltage drops significantly, and the Grid-Tied inverter shuts off after sensing a change in frequency. The solar panels connected to the Grid-Tied inverter also stops working. Now the backup hybrid inverter turns on and starts supplying power to the critical loads' panel from the batteries. Since there is an MPPT charge controller, it can accommodate power from the solar array and run the loads or charge the battery. The Grid-Tied inverter senses a new power source, thus it starts to see if the voltage and frequencies are in range, so it is tricked into working. The system starts working as an off-grid system while being disconnected from the grid. The workers will be safely repairing the line, and the house can produce power by its battery backup source.

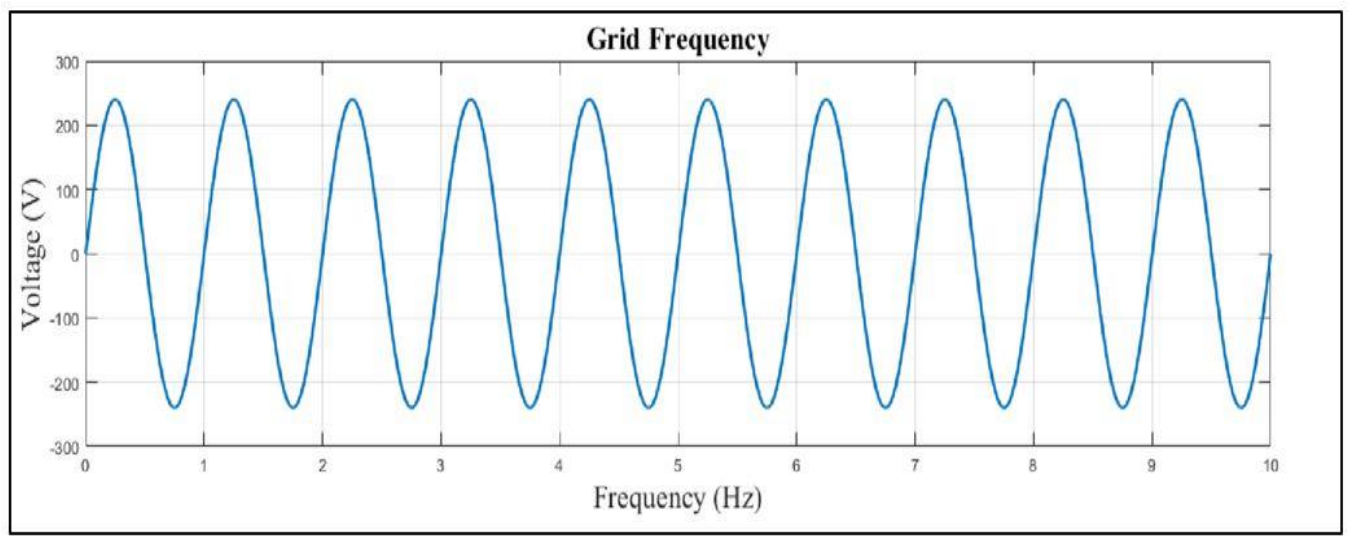

Figure 8. Grid voltage distribution

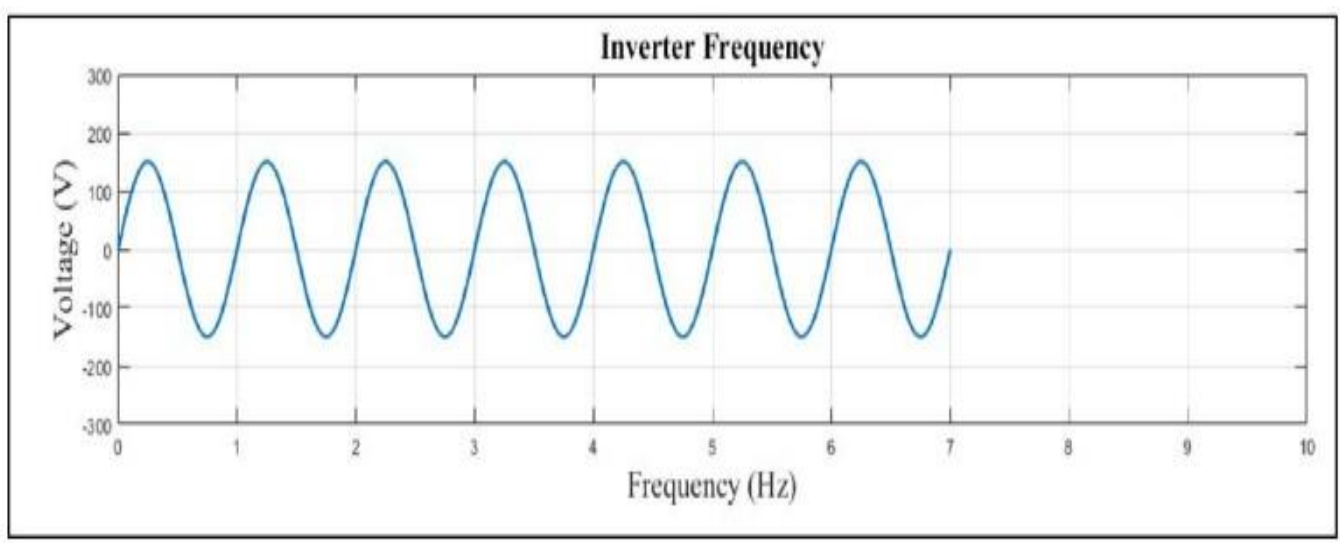

Figure 9. Inverter voltage distribution

\section{CONCLUSION}

In this work, the dynamic performance of the grid-tied battery backup system was analyzed to follow residual power fluctuations. The goal of this research was to develop a design system to help endusers identify the best investment decision and system size for their specific applications. With the use of SAM software, a program is developed to maximize saving by minimizing the electricity bill. The model is capable of identifying the feasibility of investment in PV battery systems and the specifications of the optimal system. In this design, the $\mathrm{LiFePO}_{4}$ battery offers more with high power applications. In this designed system, the round trip efficiency of the battery contributes to increasing the overall system efficiency by $2 \%$. High temperatures $30-40{ }^{\circ} \mathrm{C}$ increase the capacity but decrease the life cycle, whereas in 
low temperatures $10-20^{\circ} \mathrm{C}$, the vice versa occurs. For optimum usage of the battery, $10^{\circ} \mathrm{C}$ was used so that it would not overcharge the battery and damage its chemical properties for a better life cycle. Island detecting was also sorted out for this design. The Grid-Tied inverter works in phase with the grid voltage and frequency of $240 \mathrm{~V}$ at $60 \mathrm{~Hz}$. The shift in the frequency range above $60.2 \mathrm{~Hz}$ automatically shuts down the inverter for protection purposes, increasing the system stability. This decision support program enables the consumer to implement the most efficient electricity management strategy while achieving the goal of minimizing the electricity bill.

\section{REFERENCES}

[1] M. N. Lakhoua, et al., "System Analysis of a Hybrid Renewable Energy System," International Journal of Electrical and Computer Engineering (IJECE), vol. 4, no. 3, pp. 343-350, 2014.

[2] M. K. Panjwani, et al., "Hybrid concentrated photovoltaic thermal technology for domestic water heating," Indonesian Journal of Electrical Engineering and Computer Science (IJEECS), vol. 16, no. 3, pp. 1136-1143, 2019.

[3] S. Vavilapalli, et al., "Power Balancing Control for Grid Energy Storage System in PV Applications-Real Time Digital Simulation Implementation," Energies, vol. 10, no. 7, p. 928, 2017.

[4] G. Swaminathan, et al., "Investigations of microgrid stability and optimum power sharing using robust control of grid tie pv inverter," in Advances in Smart Grid and Renewable Energy, pp. 379-387, 2018.

[5] R. M. Larik, et al., "A statistical jacobian application for power system optimization of voltage stability," Indonesian Journal of Electrical Engineering and Computer Science (IJEECS), vol. 13, no. 1, pp. 331-338, 2019.

[6] A. Castillo and D. F. Gayme, "Grid-scale energy storage applications in renewable energy integration: A survey," Energy Conversion and Management, vol. 87, pp. 885-894, 2014.

[7] S. K. Sakiliba, et al., "Assessment of Stand-Alone Residential Solar Photovoltaic Application in Sub-Saharan Africa: A Case Study of Gambia," Journal of Renewable Energy, pp. 1-10, 2015.

[8] D. Spiers, "Batteries in PV systems," in Practical Handbook of Photovoltaics, pp. 721-776, 2012.

[9] A. Anees, "Grid integration of renewable energy sources: Challenges, issues and possible solutions," 2012 IEEE 5Th India International Conference on Power Electronics (IICPE), 2012, pp. 1-6.

[10] B. Jose, "Grid integration of PV systems-issues and requirements," 2017 IEEE International Conference on Circuits and Systems (ICCS), 2017, pp. 215-219.

[11] R. Khalilpour and A. Vassallo, "Planning and operation scheduling of PV-battery systems: A novel methodology," Renewable and Sustainable Energy Reviews, vol. 53, pp. 194-208, 2016.

[12] A. Vassallo, "Applications of batteries for grid-scale energy storage," Advances in Batteries for Medium and Large-Scale Energy Storage, pp. 587-607, 2015.

[13] M. Castillo-Cagigal, et al., "PV self-consumption optimization with storage and Active DSM for the residential sector," Solar Energy, vol. 85, no. 9, pp. 2338-2348, 2011.

[14] A. Pyrgou, et al., "The future of the Feed-in Tariff (FiT) scheme in Europe: The case of photovoltaics," Energy Policy, vol. 95, pp. 94-102, 2016.

[15] B. Lu and M. Shahidehpour, "Short-Term Scheduling of Battery in a Grid-Connected PV/Battery System," IEEE Transactions on Power Systems, vol. 20, no. 2, pp. 1053-1061, 2005.

[16] N. Kaushika, et al., "Simulation model for sizing of stand-alone solar PV system with interconnected array," Solar Energy Materials and Solar Cells, vol. 85, no. 4, pp. 499-519, 2005.

[17] J. A. Halliday, et al., "Battery management for PV systems," Power Engineer, vol. 17, no. 1, pp. 46-46, 2003.

[18] J. Appelbaum, et al., "Performance analysis of a solar-electrical system with a load and storage batteries," Energy Conversion, vol. 16, no. 3, pp. 105-110, 1977.

[19] A. Fragaki and T. Markvart, "System memory effects in the sizing of stand-alone PV systems," Progress in Photovoltaics: Research and Applications, vol. 21, no. 4, pp. 724-735, 2013.

[20] M. Pedram, et al., "Hybrid electrical energy storage systems," Proceedings of the 16Th ACM/IEEE International Symposium on Low Power Electronics and Design-ISLPED '10, 2010, pp. 363-368.

[21] M. Stadler, et al., "Optimizing distributed energy resources and building retrofits with the strategic DERCAModel," Applied Energy, vol. 132, pp. 557-567, 2014.

[22] Y. Wang, et al., "Optimal Control of a GridConnected Hybrid Electrical Energy Storage System for Homes," Design, Automation \& Test in Europe Conference \& Exhibition (DATE), pp. 881-886, 2013.

[23] IRENA, "Electricity storage and renewables: Costs and markets to 2030," 2017. [Online]. Available: http://www.irena.org/publications/2017/Oct/Electricity-storage-andrenewables-costs-and-markets.

[24] K. Zipp, "Solar batteries: Which is best for storage? Solar Power World," 2017. [Online]. Available: https://www.solarpowerworldonline.com/2015/08/what-is-thebest-type-of-battery-for-solar-storage/.

[25] P. Kurzweil and K. Brandt, "Secondary Batteries-Lithium Rechargeable Systems | Overview," Encyclopedia of Electrochemical Power Sources, pp. 1-26, 2009.

[26] P. Leung, et al., "Recent developments in organic redox flow batteries: A critical review," Journal of Power Sources, vol. 360, pp. 243-283, 2017.

[27] M. Froese, "Kokam to develop 36-MW energy storage system for KEPCO," Wind Power Engineering \& Development, 2016. 